\title{
Vivências do Balé. Um fora de foco do cartão postal do Rio de Janeiro
}

\section{Paola María Marugán Ricart ${ }^{1}$}

Resumo: No presente artigo pretendo realizar uma análise subjetiva, apaixonada e rigorosa do principal projeto do Grupo Cultural Balé das lyabás, As Vivências do Balé - Protagonismos de Preta (2013-2017), de modo a compreender de que maneiras essas práticas artísticas foram produzidas pelas marcas de suas próprias condições históricas, políticas, sociais e afetivas.

Palavras-chave: mulheres negras, feminismo negro, práticas artísticas, democracia racial

\section{Vivências of the Balé. An out of focus postcard from Rio de Janeiro}

Abstract: In this article I pretend to present a subjective, passionate and rigorous analysis of As Vivências do Balé - Protagonismos de Preta (2013-2017), which was the main project of Grupo Cultural Balé das lyabás, in order to examine how artistic practices were produced within its own historical, political social and affective context.

Keywords: black women, black feminism, artistic practices, racial democracy

1 Curadora, pesquisadora e gestora cultural independente. Estudante do programa de doutorado em Estudos Feministas da Universidade Autônoma Metropolitana, Unidade Xochimilco (UAM-X) Cidade do México. Mestra em Arte e Cultura Contemporânea pelo Instituto de Artes da Universidade do Estado do Rio de Janeiro (PPGARTES/ UERJ). Tem publicado o livro "Transarquivo: uma escrita revolucionária de relatos da história da arte". Curitiba: CRV, 2018. Tem realizado curadorias no Museo Universitario del Chopo (CDMX), Instituto Goethe -Salvador (Bahia), A Caixa Cultural (RJ), Galeria Balaguer (Barcelona), CaixaForum (Barcelona), entre outros. Universidad Autónoma Metropolitana, Unidad Xochimilco (UAM-X). E-mail: paolamarugan@gmail.com. ORCID: https://orcid.org/00000002-0767-1988. Lattes iD: http://lattes.cnpq.br/5144395448620223. Cidade do México, México 


\section{Introdução}

No presente artigo pretendo realizar uma análise subjetiva, apaixonada e rigorosa do principal projeto do Grupo Cultural Balé das lyabás, As Vivências do Balé - Protagonismos de Preta (2013-2017), a partir da minha participação eventual, em algumas das sessões entre os anos 2015 e 2016, de modo a continuar compreendendo o impacto que esses encontros tiveram no meu processo de subjetividade, enquanto pesquisadora feminista e antirracista, oriunda do norte global ${ }^{1}$.

Neste texto intentarei compreender de que maneiras as práticas artísticas do Balé das lyabás foram produzidas pelas marcas de suas próprias condições históricas, políticas, sociais e afetivas. A meu ver, no decorrer das Vivências do Balé foi se conformando um sujeito político (individual e coletivo), capaz de interpelar o modelo de nação brasileira, racista, sexista e colonial, nas suas figurações contemporâneas. A miscigenação, enquanto mito fundacional organizador de mundo, foi engendrada por meio da violência e a dominação, apesar de ter sido elaborada historicamente sob retóricas de reconciliação. Observar a mestiçagem no Brasil é compreender de que maneiras a nação foi organizada territorialmente conforme o marcador racial. O mito da democracia racial tornou-se a possibilidade material de atingir um pacto civilizatório, a partir de uma narrativa de futuro branqueado e segundo uma série de convenções sociais de falsa convivência harmônica. Assim, compreendo que a democracia racial foi o mito apaziguador das relações sociais, sustentado por um sistema-mundo profundamente violento, que até hoje, mantém seus alicerces fortalecidos pelas políticas depredatórias do atual (anti)-presidente (2018-). Abdias Nascimento apontava, já na década dos setenta:

O preconceito de cor, a discriminação racial e a ideologia racista permaneceram disfarçados sob a máscara da chamada "democracia racial", ideologia com três principais objetivos. 1. Impedir qualquer reivindicação baseada na origem racial daqueles que são discriminados por descenderem do negro africano; 2. Assegurar que todo o resto do mundo jamais tome consciência do verdadeiro genocídio que se perpetra contra o povo negro do país; 3 . Aliviar a consciência de culpa da própria sociedade brasileira que agora, mais do que nunca, está exposta à crítica das nações africanas independentes e soberanas, das quais o Brasil oficial pretende auferir vantagens econômicas. (NASCIMENTO, 1976/2018: 34)

1 Este artigo faz parte da introdução de minha pesquisa de doutorado, no programa de Estudos Feministas na Universidade Autônoma Metropolitana, unidade Xochimilco (UAM-X), Cidade do México. 
A análise deste artigo organizou-se a partir da apresentação do projeto do Balé e do que eu chamei, o fora de foco do cartão postal da cidade do Rio de Janeiro, para depois aprofundar no projeto das Vivências e finalmente, concluir com uma reflexão a modo pessoal (levando em consideração que o pessoal é político) sobre a dimensão ética e política das minhas práticas.

\section{O Balé das lyabás. Um fora de foco do cartão postal do Rio de Janeiro}

No imaginário coletivo transnacional, a primeira imagem do Rio de Janeiro é o clássico cartão postal do Pão de açúcar, a praia de Copacabana e o Cristo Corcovado no fundo, abençoando a cidade e dando generosamente a bem-vinda aos recém-chegados na Bahia de Tijuca. Aliás, que cidade é essa que o Corcovado rende homenagem? A resposta encontra-se esculpida na gramática corporal da estátua. Seus braços abertos, o coração e o olhar são dirigidos à zona sul da cidade. Os outros "rios de janeiro" são as costas do Cristo Redentor, de modo que ainda não receberam sua benção. São os banidos ao eterno "waiting-room" (CHAKRABARTY, 2009) das promessas civilizatórias (ordem e progresso) da modernidade. E justamente são as próprias lógicas estruturantes da modernidade colonial que impedem o corpo de Cristo produzir um olhar multifocal. Aquilo inatingível diante dos olhos do Corcovado conforma-se enquanto um "exterior constitutivo" a partir de "uma série de exclusões que aliás, são internas desse sistema" (BUTLER, 2002: 71).

\footnotetext{
Modernidade e colônia (centro-periferia, norte-sul)2, afinal de contas, eram elementos co-constitutivos de uma ordem capitalista mundial em alta. (...) Esta modernidade capitalista -termos indissolúveis vinculados em mais de um sentido - esbarrou sua realização, embora muito desigualmente no arcabouço das grandes aspirações do liberalismo, na arquitetura político-jurídica da democracia, o "livre" mercado, os direitos civis e a sociedade civil, a sociedade de direito, a separação entre o público e o privado, o secular e o sacro. (COMAROFF; COMAROFF, 2013: 20-22)
}

No "exterior constitutivo" do cartão postal do Rio forma-se, no ano 2012, o Grupo Cultural Balé das lyabás. Uma iniciativa de um grupo de mulheres negras, que buscam refletir acerca do protagonismo da mulher e sobretudo, da mulher negra na sociedade contemporânea brasileira. Em 2012, após dez anos do Partido dos Trabalhadores (PT) no governo estatal e viver "um dos 
maiores esforços da política brasileira no sentido da inclusão social da maioria da população secularmente esquecida" (SOUZA, 2016: 52), o país entrava no que seria a primeira crise social, econômica e política do século vinte-um. Em junho de 2013, uma série de manifestações populares surpreenderia o país, tomando as ruas de várias cidades, por meio dos hashtags \#GiganteAcordou e \#BrasilAcordou, reavivando a potência global das recentes rebeliões acontecidas no norte da África e no sul da Europa. Poucas vezes houve no Brasil uma reivindicação popular de tais dimensões, congregando pessoas de múltiplas identidades e diferentes posicionamentos ideológicos, sob o lema "Um Brasil melhor e mais justo". O Movimento Passe Livre organizou a primeira marcha, de modo a defender a gratuidade do transporte público e contra o aumento do $\mathrm{R} \$ 0,20$ nas tarifas do metrô e o ônibus. As manifestações foram fortemente reprimidas pelo corpo da Polícia Militar, desencadeando uma crise social e política, que levou a uma grande parte do país a denunciar a suposta corrupção do governo da presidenta Dilma Rousseff (2011-2016), revigorando o movimento Direitas já e produzindo um deslocamento no significado desse movimento acontecido durante o período de Apertura Democrática (1984-1986). Tais ações podem ser lidas enquanto linhas de fuga que ressurgem nas cartografias do social, desestabilizando as lógicas alegadamente continuístas dos processos históricos. A precarização galopante das condições de vida da cidadania gerou um profundo mal-estar no terreno da subjetividade, ativando a pulsão vital das/dos/des sujeitos, convocados pelo desejo e a urgência de reestabelecer o equilíbrio.

Nessa conjuntura surge o Grupo Cultural Balé das lyabás com a estreia do primeiro espetáculo Mito no Cotidiano: O Balé das lyabás, apresentado por Ludmila Almeida, Sinara Rúbia e Ana Flávia Vieira³, como parte da programação de MOLA-Mostra livre de Artes, no Circo Avoador, no bairro da Lapa do Rio de Janeiro. Apesar de serem duas artistas-articuladoras, a formação do grupo é definida enquanto coletivo.

O Grupo Cultural Balé das lyabás é um grupo de Mulheres Negras que propõe a reflexão sobre o protagonismo da mulher na sociedade a partir da mitologia dos Orixás. Pensando a arte de forma política, trabalhamos com as questões de gênero e raça tendo como missão o fortalecimento, emancipação e empoderamento de mulheres, sobretudo Mulheres Negras, por compreendermos as demandas diferenciadas desse grupo e a consequente necessidade de iniciativas que deem a atenção necessária a este segmento da população4.

3 Ana Flávia abandona o grupo em 2013.

4 Trecho extraído do Release do grupo, que as mesmas artistas compartilharam com a 
O Balé, por meio de uma pesquisa interdisciplinar de dança, literatura e mitologia do Candomblé, desenvolve projetos em que refletir sobre o protagonismo da mulher negra na sociedade atual, discutindo os marcadores de raça, gênero e classe social, de modo a contribuir ao fortalecimento e à emancipação das mulheres negras. Em uma entrevista, Ludmila Almeida comenta:

As mulheres negras têm toda essa trajetória, esse histórico de resistência desde sua chegada até aqui, a partir de seus cultos, sua vida, sua memória, sua ancestralidade... A gente pode ter todo esse referencial que a gente tem no Candomblé, no Brasil hoje, que é o ponto de partida do Grupo Cultural Balé das lyabás (...). Nos entendemos o nosso trabalho não só como um trabalho artístico, mas como um trabalho político, social, cultura e de reflexão dessas questões da mulher na sociedade brasileira. Enquanto a gente tem essas questões muito fortes, a gente precisa ultrapassar cotidianamente desde a que a gente acorda, liga a televisão e não se vê representada, desde que a gente sai na rua e escuta piadinhas por conta do nosso cabelo, desde que a gente vê as nossas crianças querendo ser brancas, porque esse é o referencial de beleza e civilidade (...). Isso é uma questão que mina nossa autoestima desde pequenas.5

O nome do grupo, Balé das lyabás, é uma homenagem às mulheres africanas que chegaram forçadamente no Brasil durante o período da escravidão. Estima-se que aproximadamente zinco milhões de africanas/africanos chegaram no país, sendo o Rio de Janeiro a cidade que mais navios recebeu, segundo afirma Mercedes Guimarães do Instituto de Pesquisa da Memória dos Pretos Novos do RJ ${ }^{6}$. Iyabás significa mãe-rainha e é o modo de nomear as orixás femininas, lansã, Oxum, Nanã, lemanjá... A meu ver, essa homenagem é também uma forma de interpelar o imaginário coletivo, que apenas concebe as figuras dessas mulheres e homens africanos enquanto escravizados, apagando as múltiplas histórias de resistência e insurreição, acontecidas durante o período escravocrata-colonial. Esse imaginário tem sido sustentado e reproduzido ad infinitum pelas disciplinas clássicas (ciências naturais, ciências sociais, a arte e a literatura) enquanto instituições que organizam e avaliam a produção de conhecimento.

Entretanto, os estudos críticos dirigidos à análise das relações raciais, aunando a modo interdisciplinar, projetos pedagógicos, antropológicos e so-

autora deste artigo.

5 Entrevista no programa "Para Todos" da TvBrail, realizada o dia 6 de junho de 2015. Disponível: https://tvbrasil.ebc.com.br/paratodos/episodio/a-primeira-dama-do-samba-dona-ivone-lara-esta-no-paratodos\#media-youtube-1 A partir do minuto 13' 21".

6 Informação disponível aqui: http://pretosnovos.com.br/ 
ciológicos, vêm se desenvolvendo já da década dos setenta, sobretudo em São Paulo (USP) e no Rio de Janeiro (UFRJ). A produção de pensamento (enquanto ação e reflexão) da historiadora e ativista Beatriz Nascimento libertou a negritude do encerramento conceitual acadêmico, que apenas pensava o passado escravocrata, de modo a ressignificar os signos e propor outras maneiras de abordar as múltiplas questões que produzem as vidas negras. Na Quinzena do negro na USP (1977), organizada por Eduardo Oliveira Oliveira (intelectual, poeta, ativista do movimento negro), Nascimento apresentou uma palestra, intitulada Conferência Historiografia do Quilombo, em que mostrava sua preocupação pelo recorte nos estudos raciais da academia brasileira:

Quando cheguei na Universidade a coisa que mais me chocava era o eterno estudo sobre o escravo. Como se nós só tivéssemos existido dentro da nação como mão de obra escrava, como mão de obra pra fazenda e pra mineração. (NASCIMENTO em RATTS, 2006: 41)

O Balé adscreve-se ao movimento feminista negro brasileiro, que conta com um vasto histórico de lutas ${ }^{7}$, frequentemente invisível nas narrativas históricas hegemônicas, que atuam em cumplicidade com o mito fundacional da nação e a branquitude, enquanto programa moderno-colonial, e possuem o poder do "teto todo seu" -em palavras de Virginia Wolff, a escritura e a publicação ${ }^{8}$. Djamila Ribeiro (2017) aponta para a necessidade de tornar visível o marcador racial dentro do movimento feminista, de modo a sublinhar a impossibilidade de conceber o seu sujeito político sem um posicionamento antirracista. Assim, o feminismo negro significaria que as mulheres racializadas estão ensaiando, segundo a lógica de "pensar-sentir-fazer" -como gostava de dizer Audre Lorde, modelos alternativos de sociedade e não apenas questões relacionadas com as comunidades negras. A meu ver, uma das contribuições principais do feminismo negro é o

7 No final do texto apresento dois diagramas, um, do movimento feminista brasileiro e outro, do movimento feminista brasileiro negro, que realizei para a pesquisa de mestrado no PPGARTES/UERJ, 2014-2016, sob a orientação da Dra. Denise Espírito Santo.

8 Um exemplo entre muitos é o livro de Céli Regina Jardim Pinto (2003). Uma história do feminismo no Brasil. São Paulo: Fundação Perseu Ábramo, cujo modelo de historicização é baseado nas conhecidas "ondas" do feminismo oriundo do norte global. Me parece interessante a problematização que trazem Tauana Olívia Gomes Silva e Gleidiane de Sousa Ferreira no artigo "E as mulheres negras? Narrativas históricas de um feminismo à margem das ondas”, publicado pela revista Estudos Feministas, Florianópolis, 25 (3), 2017, pp. 1017-1033, em que colocam em xeque o deslocamento acrítico desse modelo nas análises históricas dos feminismos brasileiros. 
pensamento interseccional, por trazer uma compreensão abrangente das múltiplas opressões que constituem a produção de corpos-vidas e que são assim mesmo estruturantes e estruturais do sistema-mundo colonial, não sendo uma mais importante do que a outra, porém atuando no mesmo regime de co-constituição dos sujeitos -como precisamente aponta Maria Lugones (2014).

\begin{abstract}
Por isso, uma vez que a interseccionalidade mostra o que é perdido, temos pela frente a tarefa de re-conceituar a lógica da intersecção para, desse modo, evitar a separabilidade das categorias dadas e o pensamento categorial. Só percebendo o gênero e a raça enquanto tecidos e fusionados indissoluvelmente, nos podemos realmente ver as mulheres de cor (...) A lógica dos eixos estruturais mostra o gênero como constituído por e constituindo à colonialidade do poder. Nesse sentido, não existe separação de raça/gênero no padrão de Quijano e acho que a lógica que apresenta é a correta. (LUGONES, 2014: 21-22)
\end{abstract}

Os movimentos feministas plurais no Brasil adquiriram diferentes contornos a partir da década dos oitenta ${ }^{9}$, durante o processo de Apertura Democrática, após a ditadura cívico-militar (1964 - 1986), que aterrorizou e violentou o país durante mais de vinte anos. Algumas pesquisadoras, como Luana Diana dos Santos (2013), consideram que uma "segunda abolição" foi iniciada naqueles anos, por meio de ações coletivas e individuais levadas a cabo na ordem do quotidiano (DIANA DOS SANTOS, 2013: 226). De facto, existem materializações importantes, resultado deste segundo "processo abolicionista", como a aprovação do Estatuto de Igualdade Racial $(2010)^{10}$, a criação da Secretaria de Igualdade e a implementação da Lei 10.639 (2003), que passava a exigir a incorporação do ensino de história e cultura afro-brasileira e indígena, nas currículas das escolas públicas e particulares. Essa lei foi a pedra de toque para o desenvolvimento de um extenso programa de ação afirmativa no sistema de ensino, que supôs a implementação das políticas de quotas e bolsas para estudantes racializadas/os/es e procedentes de famílias de renda baixa, em todas as universidades do país.

9 Importa salientar alguns dos projetos com maior relevância como o Grupo Luiza Mahin (Río de Janeiro, 1980), o Coletivo de Mulheres Negras (São Paulo, 1983) e Geledés- Instituto da Mulher Negra (São Paulo, 1988), entre outros muitos...

10 A Lei № 12.288, 2010 institui o Estatuto de Igualdade Racial, destinado a garantir a efetividade da igualdade de oportunidades à população negra, a defesa dos direitos étnicos individuais, coletivos e difusos e o combate à discriminação e as outras formas de intolerância étnica. 
$\mathrm{O}(\mathrm{s})$ sujeito(s) político do feminismo negro enfrentou por um lado, o pensamento patriarcal do Movimento Negro Unificado (MNU), com um projeto político que jamais considerou a variável de gênero um assunto importante para ser discutido e por outro, a resistência das mulheres com privilégio de branquitude do movimento feminista hegemônico, a incluírem as discussões debruçadas para os processos de racialidade e de marginação social das mulheres negras brasileiras, resultado de uma soma de percursos históricos, que vêm do período escravocrata, da formação do projeto nacional baseado no mito da convivência "harmônica" das três raças e da necropolítica, que definiu a ditadura cívico-militar. Uma das pioneiras em problematizar esse feminismo hegemônico foi a militante intelectual Lélia González, que trabalhou pela descolonização do movimento, colocando em xeque a hierarquização dos saberes, herdada da organização social do sistema-mundo colonial. Lélia compreendia que o privilégio epistémico era concomitante do privilégio social do lugar de fala do sujeito. Ela defendeu o pretuguês como um tipo de língua oficial, falada pelas comunidades afro-brasileiras, de modo a questionar os imperativos epistémicos da empresa colonial, que desconsiderava (até a obliteração) todos os saberes e formas de expressão linguística e cultural dos povos não ocidentais. (RIBEIRO, 2017; DIANA DOS SANTOS, 2013; GONZÁLEZ, 1994; GOMES SILVA, DE SOUSA FERREIRA, 2017).

Nos percursos desta pesquisa encontrei múltiplas compreensões da categoria "mulher negra", enquanto sujeito político do movimento feminista negro. Ela ("o outro do outro" -segundo Grada Kilomba (2019)) prestou para assinalar a realidade invisível das mulheres negras nos espaços públicos de poder, além de trazer consigo a reivindicação do direito à própria vida. Interessante é a provocação de Jurema Werneck (2016):

As mulheres negras não existem. Ou falando de outra forma: as mulheres negras,
como sujeitos identitários e políticos, são resultado de uma articulação de heteroge-
neidades, resultante de demandas históricas, políticas, culturais, de enfrentamento
das condições adversas estabelecidas pela dominação ocidental eurocêntrica ao lon-
go dos séculos de escravidão colonial e da modernidade racializada e racista em que
vivemos. (WERNECK, 2016: 151-152)

Mulher negra é uma categoria produzida por múltiplos e complexos processos de racialização, impostos e materializados nos corpos-vidas das muIheres. Essas heterogeneidades, que apontava Werneck, adquiriram maior visibilidade na areia pública, durante o ano da comemoração do centenário da abolição da escravidão (1988), graças a um vasto programa de atividades de encontros, palestras, exposições de arte, publicações de livros, 
peças de teatro e dança, de modo a produzir conhecimento voltado para as problemáticas específicas das vidas negras, tais como a ancestralidade africana, religiosidade, oralidade, história/memória, violência (estatal e doméstica), políticas públicas (sistema de saúde, moradia, educação, transporte), estética, corporalidade, sexualidade e desejo. Assuntos, que trinta anos depois, continuarão a ser de caráter urgente no programa das Vivências do Grupo Cultural Balé das lyabás.

\section{As Vivências do Balé - Protagonismos de Preta}

As Vivências do Balé - Protagonismos de Preta é um projeto que o Grupo Cultural Balé das lyabás começou a realizar em 2013 até 2017, principalmente no bairro de Santa Teresa, Rio de Janeiro. As Vivências eram um espaço permanente de diálogo e reflexão voltado para sentir-pensar o protagonismo das mulheres negras na sociedade brasileira contemporânea e sobretudo, as formas de fortalecimento desses corpos no enfrentamento das violências do quotidiano ${ }^{11}$.

Um domingo por mês, Ludmila Almeida e Sinara Rúbia convocavam as Vivências no Centro Cultural Laurinda Santos Lobos, um espaço localizado em um casarão de estilo colonial no bairro de Santa Teresa. Construído em 1907, no florescimento da chamada Belle Époque carioca, o centro conta com uma sala de exposições, um jardim meio abandonado e uma sala de ensaio com um pequeno palco. Laurinda Santos Lobo foi uma mecenas muito reconhecida, no âmbito artístico carioca das primeiras décadas do século XX. Sua casa tornou-se um lugar de encontro para o movimento modernista, em que organizava festas, exposições, espetáculos de

11 O governo de São Paulo publicou alguns dados registrados sobre violência a um nível federal. Entre 2011-2018 houveram 145 mil casos de violência física, sexual, psicológica e de outros tipos. 0 68\% desse valor é violência contra as mulheres (22.432 casos de violência sexual e 37.414 de violência psicológica). 7 de cada 10 vítimas são crianças e jovens (até 19 anos). Os estupros sexuais coletivos foram de 3.837 casos. O Instituto de Pesquisa Econômica (IPEA), o Fórum Brasileiro de Segurança Pública (FBSP) e o Ministério de Saúde -com o projeto Atlas da Violência- publicaram a seguinte informação registrada de 2017. Das 4.936 mulheres assassinadas esse ano, o 66\% eram negras, de modo que houve um aumento de violência contra as mulheres negras na última década, apesar da existência da Lei N¹1.340 Maria da Penha, 2006 (que reduziu um 10\% de casos de violência contra as mulheres brancas e/ou mestiças) e da Lei №13.104 de Feminicídio, 2015. 
dança, teatro e música. Laurinda defendeu os direitos civis das mulheres (brancas, é importante frisar) e chegou a presidir a Federação Brasileira para o Progresso Feminino. Desta maneira, o centro cultural inscreve-se em uma constelação de lutas feministas e femininas no campo artístico e cultural, que não apenas dialogava com o espírito das Vivências, porém o problematizava, no sentido de reescrever a(s) história(s) daquele espaço, a partir da própria enunciação dos corpos das mulheres racializadas lá presentes, participando e reconhecendo sua humanidade por meio da dança, a mitologia e a espiritualidade.

A permanência do projeto durante esses anos foi graças ao edital Fale Sem Medo do Instituto Avon, no XIX Concurso ELAS Fundo do Investimento Social ${ }^{12}$. Esse edital nasceu de uma parceria entre o Instituto Avon e ELAS-FIS, tendo como intuito o enfrentamento da violência contras as mulheres, por meio da criação de projetos dedicados à transformação social e ao fortalecimento das mulheres na sociedade atual. O fato do Balé das lyabás ter sido contemplado duas vezes nesse edital (a primeira: 2014-2015; a segunda: 2016-2017), permitiu a criação e consolidação de um espaço de encontro e diálogo para as mulheres, que visava incidir nos processos de subjetivação social de mais longo prazo.

Em cada Vivência, Ludmila e Sinara convidavam uma mulher negra atuante em alguma área de interesse para a comunidade, tal como psicologia, jornalismo, pedagogia, arte, ativismo, tecnologia, entre outras ${ }^{13}$. A entrada era livre, aliás, as artistas pediam uma colaboração de $R \$ 10$ ou $R \$ 20$, dependendo das possibilidades de cada participante. As participantes de cada Vivência acostumavam ser mulheres e principalmente mulheres negras, embora às vezes encontrasse algum homem e mulheres brancas ou mestiças também. $\mathrm{O}$ acesso não era restrito para ninguém. Essas mulheres encontravam-se entre os 25 e 50 anos de idade. Muitas delas tinham

12 http://www.fundosocialelas.org/falesemmedo/

13 A seguir, algumas das convidadas: Vanda Ferreira (assessora na Secretaria Especial de Políticas Públicas de Mulheres), Flávia Oliveira (jornalista, comentarista da Globo News e colunista do jornal O Globo), Rosângela Castro (ativista lésbica negra nos grupos Felipa de Sousa, ABL e Articulação Brasileira de Lésbicas), Mafoane Odara (psicóloga e coordenadora da área de enfrentamento à violência no Centro das Mulheres do Instituto Avon), Vanessa Menezes de Andrade (psicóloga e coordenadora do projeto Afrobetizar), Patricia Alves (lya Suru-lyalorixá do llê Axê lya Mi Agbá, pedagoga e coordenadora de educação no Instituto Omalaba Brasil), Valeria Monã, Aline Valentim G'leu Cambria e Ana Catão (professoras e lideranças das Danças Negras - Dança Afro do Rio). 
formação acadêmica -havendo sido beneficiárias do programa público de quotas e bolsas para estudantes universitárias/os racializadas/os, implementado pelo governo do PT (Partido dos Trabalhadores) ${ }^{14}$, e algumas mostravam uma profunda consciência política feminista e antirracista. Segundo Ludmila ${ }^{15}$, as mulheres que participavam das Vivências procuravam trocar experiências e conhecimento, afetividade e reforço de suas identidades. Várias delas vinham no encontro com suas/seus filhas/filhos e companheiros, de modo a fortalecerem os núcleos familiares, enfraquecidos pelos processos de desumanização experimentados cotidianamente.

As sessões começavam no chão. Todas as mulheres sentadas em forma de círculo. Ludmila e Sinara inauguravam as Vivências com as apresentações, primeiro elas e o projeto do Balé, sem demora, a convidada daquele dia. A seguir, todas as participantes se apresentavam respeitando a ordem circular e finalmente, a convidada compartilhava o seu trabalho, suas estratégias de enfrentamento as violências do quotidiano, as formas de re-existir/resistir/resilir de cada dia e em geral, sublinhava a dimensão política dos seus afazeres, pela consciência de ser uma mulher negra, morando em uma sociedade com tintas coloniais e portanto, profundamente desigual e discriminatória.

Logo depois, o grupo dividia-se em subgrupos de 4-5 mulheres, de modo a realizar uma leitura de textos escolhidos pelas artistas, que correntemente acostumavam ser relatos da mitologia do Candomblé. A tarefa consistia em prestar uma leitura coletiva, observando com especial atenção as relações de poder apresentadas neles, para seguidamente, expor essas ideias com o resto dos grupos. A partir dai, o debate era aberto, para o coletivo discutir todas essas questões e pô-las em relação com as experiências de vida das participantes. Segundo os meus referenciais, estes debates lembravam os grupos de autoconsciência feminista, surgidos nos Estados Unidos (principalmente em Nova York e Califórnia), no final da década dos sessenta ${ }^{16}$. Estes grupos tornaram-se espaços de produção de conhe-

14 Importa salientar que essas políticas já foram implementadas em algumas universidades no governo de Fernando Henrique Cardoso (1995-2003) e além do mais, eram parte da agenda política do movimento negro e das lutas feministas das mulheres negras. Considero importante sublinhar esse "detalhe" justamente para evitar o velamento dos processos históricos das lutas dos movimentos sociais e de resistência.

15 Ibid, 5.

16 Uma referência bibliográfica interessante destes grupos de autoconsciência, Kathie 
cimento de/para mulheres, a partir de compartilhar e analisar suas experiências quotidianas (quase todas elas com privilégio de branquitude), de modo a compreender as relações estreitas entre a organização estrutural do mundo e suas estórias de vida.

Sem dúvida, Ludmila e Sinara devem ter emplacado esse exercício em outras genealogias de práticas e saberes de mulheres negras brasileiras, diaspóricas e africanas. De qualquer modo, o debate aberto e coletivo contribuía a desenvolver uma consciência feminista e antirracista, que as levava à ação (micro)política. As experiências das participantes podiam se organizar segundo os regimes de ódio, operantes nos diferentes cenários da vida (escola, hospital, família, comunidade, trabalho...) e portanto, suas estratégias de enfrentamento e fortalecimento eram produzidas conjuntamente, pois as mulheres sentiam-se reconhecidas nas experiências das outras. Essa era uma forma de confrontar a solidão produzida pela vivência constante do racismo estrutural, institucional e quotidiano.

Trazer a experiência na areia da discussão (científica, social, política) foi um das grandes contribuições das feministas de diferentes geopolíticas, enquanto testemunha das formas de opressão, domínio e resistência das múltiplas sujeitas, que representam a Otredade. As experiências das muIheres foram uma ferramenta para tornar visível relações de poder naturalizadas, por um sistema, que concomitantemente gera(va) subalternidade e torna(va) invisível as estruturas disciplinantes que a provocavam (TREBISSACE, 2017). Falar em experiência implica considerar o perigo da essencialização nos processos de produção de conhecimento. Nos debates das Vivências, o relato experiencial apresentava-se como a verdade do sujeito falante, e quanto era nesses corpos!, porém a abordagem dessa verdade era sempre discutida de maneira contextual e contingente. Compreender isso implicava levar em consideração as complexas relações de poder que tem produzido e produzem hoje a categoria mulher negra enquanto a "outra do outro" (Grada Kilomba), mas também uma sujeito de luta.

Durante os debates, a escuta radical e amorosa sentia-se uma urgência. "Hacer del hablar un intercambio de escuchas" (fazer do falar uma troca de escutas) (Rivera Cusicanqui, 2018: 43) estava no alicerce das dinâmi- 
cas do Balé. As escutas corporais (disponibilizar o corpo para se deixar afetar por) possibilitavam ao grupo produzir um sentir-pensamento fortalecedor para ser levado ao dia a dia das mulheres. O processo de desumanização, que vem se produzindo dos tempos da escravidão e a colonização, tem ainda hoje um forte impacto nos processos de formação das subjetividades das pessoas racializadas. Essa troca de escutas gerava um arcabouço de produção de saberes multidisciplinais, em que o corpo era compreendido sem cisões e em uma relação orgânica com os outros seres vivos da biosfera.

Aos poucos, o projeto tornou-se um espaço de acolhida, confiança e segurança, em que muitas mulheres se sentiam motivadas para compartiIharem as histórias pessoais com o grupo. Vivências entrelaçou processos afetivos, políticos e de produção cultural.

\begin{abstract}
As mulheres negras no Brasil ainda hoje sofrem as consequências de uma sociedade escravocrata, em que foram objetivadas como mercadoria de trabalho manual, doméstico e sexual. Cedo aprendemos que somos mulheres fortes, que devemos servir ao trabalho e nunca nos foi dada a possibilidade de sermos frágeis, como as mulheres brancas. Também aprendemos cedo que o abandono e a solidão são parte da realidade de muitas mulheres negras. Elas dirigem sozinhas suas vidas, famílias e filhos, com a ajuda de mães, avós e outras mulheres das nossas redes de cuidado e sororidade. Aprendemos a odiar os nossos traços, o nosso cabelo e a nossa cor da pele. De que maneira pensar em amor com essa realidade imposta de dor? ${ }^{17}$
\end{abstract}

Dar-se tempo e espaço para estar juntas era a base deste projeto. $\mathrm{O}$ ambiente acostumava ser festivo. A celebração girava em torno à possibilidade de mais uma Vivência estar acontecendo, a oportunidade de compartilhar o encontro com a convidada desse dia e fundamentalmente, o fato de estar vivas. A palavra vivência e sua derivada do latim é vivere, existir, subsistir, não estar morta. Comemorar a vida em um contexto de genocídio das comunidades afro-brasileiras é um ato político. Apesar das conquistas atingidas em matéria de direitos sociais, durante os mandatos do ex-presidente Lula da Silva (2003-2011), a obliteração de corpos negros nas periferias das cidades nunca cessou, sendo a Polícia Militar do Rio de Janeiro um dos corpos institucionais que maiores denuncias acumula de violação dos direitos humanos e corrupção ${ }^{18}$.

17 Entrevista realizada a Ludmila Almeida no programa "Estudo Móvel" da TVBrasil, o 14 de novembro de 2016.

18 A imprensa internacional publicava esta matéria em 2017: https://www.nytimes. com/es/2017/07/10/espanol/america-latina/los-policias-de-rio-de-janeiro-servir- 
Desta maneira, o fora de foco do cartão postal da cidade funciona sob um regime de medo constante, sustentado por diversos eixos, por um lado, as guerras entre os comandos do tráfico (comando Vermelho, Terceiro Comando Puro, Amigos dos Amigos) e por outro, as intervenções profundamente violentas da Polícia Militar e as chamadas milícias, uma problemática de extrema complexidade. A meu ver, é possível escutar os ecos desse regime nas políticas da plantação do período colonial. Achille Mbembe apontava:

\footnotetext{
No entanto, o que caracteriza a plantação não são somente as formas fragmentadas de submissão, a desconfiança, as intrigas, as rivalidades e os ciúmes, o jogo movediço das alianças, as tácticas ambivalentes feitas de cumplicidades, esquemas de toda a espécie e feitio, as condutas de diferenciação num pano de fundo de posições reversíveis. É também o facto de o vínculo social de exploração não ser dado logo de uma só vez. Vai sendo constantemente posto em causa e é incessantemente produzido e reproduzido por meio de uma violência de tipo molecular que sutura e satura a relação servil. (...) A plantação transforma-se gradualmente numa instituição econômica, disciplinar e penal. Os negros e os seus descendentes serão, desde então, comprados para sempre. (MBEMBE, 2014: 41-42)
}

O projeto de higienização étnico e racial da nação brasileira foi adquirindo diferentes contornos conforme os requerimentos políticos das elites em cada conjuntura específica. Após a abolição da escravidão ${ }^{19}$, uma enorme massa de pessoas negras libertas ocupavam as ruas das cidades em condição miserável, resultado da violência física e simbólica sofrida durante a colônia. Segundo conta Maria Aparecida Silva Bento (2002), o novo estado brasileiro criou uma política de migração europeia, trazendo 3'99 milhões de pessoas oriundas de diferentes partes desse continente (oferecendo boas condições laborais e até terras para serem ministradas por eles mesmos), em um período de trinta anos, um valor equivalente às/aos africanas/nos que chegaram forçadamente no Brasil, durante os trezentos anos anteriores. Entretanto, um século depois, as políticas de extermínio podem ser lidas através de uma lente aumentada, de modo a incluir o gênero, a classe social e a questão etária. A violência estatal imprime-se nos corpos dos homens jovens racializados, moradores das favelas principalmente, contanto que as mulheres sofrem violência sexual, criminaliza-

-proteger-matar-y-morir.html

19 A Lei do Ventre Livre do 28 de setembro de 1871, libertou os filhos nascidos de mãe escravas a partir desse momento. A Lei dos Sexagenários do 28 de setembro de 1885, libertou os escravos de sessenta anos em adiante. A Lei Áurea do 13 de maio de 1888 poria fim à escravidão. 
ção do aborto e esterilização. Esta última prática começou a ser usada de forma massiva durante a década dos oitenta, sobretudo com as mulheres de classes populares, oriundas do norte e o nordeste do país. Parece que a esterilização foi parte do programa de políticas públicas de um governo federal que passava por um processo de apertura democrática. Aliás, por mérito das lutas das mulheres feministas do movimento negro, esse projeto de extermínio foi investigado, graças à criação da Comissão Parlamentar Mista de Inquérito (CPMI) em 1991, que tinha o intuito da reparação desse tipo de atrocidades (RIBEIRO, 2017) 20.

A leitura coletiva da mitologia nas Vivências era posposta em um arcabouço de pensamento feminista negro, de modo a discutir as vicissitudes das mulheres no âmbito do quotidiano e colocar em xeque as interpretações hegemônicas da realidade mito-poética do Candomblé. Contavam, que quando os orixás chegaram na Terra, a celebração da primeira reunião política foi organizada apenas para as entidades masculinas. Oxum, muito zangada, condenou à esterilidade a todos os varões presentes, até eles permitirem participar as lyabás em todas as atividades públicas. A partir dessa leitura, Sinara e Ludmila salientavam a importância das figuras femininas na participação política. Tratava-se, portanto, de estabelecer um diálogo voltado para pensar as relações entre o universo mitológico do Candomblé e as figurações contemporâneas que moldavam os corpos das mulheres, visando fortalecer sua presença e participação em todas as dimensões da vida pública. As artistas destacavam a importância de reconhecer e valorizar a ancestralidade, história, religiosidade e cultura negra, robustecendo os saberes das mulheres por serem sua base de compreensão do mundo.

Após o debate, as artistas propunham meia hora de descanso para beber, comer fruta e doces (que elas ofereciam às participantes) e conversar em

20 É interessante observar que as feministas do movimento negro brasileiro, na década dos noventa, trouxeram à areia política as questões voltadas para a saúde e os direitos reprodutivos. Em virtude destas lutas, durante o governo de Fernando Henrique Cardoso (1995-2002) foi aprovada a Lei No 9.263 de Planejamento Familiar, 1996. De qualquer modo, parece que a CPMI não acabou de esclarecer em documento nenhum se a esterilização foi parte de um programa público de políticas estatais ou não. Djamilia Ribeiro (2017) afirma este fato sem fornecer nenhum dato oficial. Para outros posicionamentos neste debate, anexo este documento: https://www.cafehistoria.com.br/a-questao-da-saude-reprodutiva-e-o-feminismo-negro-no-brasil/ 
um tom mais relaxado entre as pessoas ali presentes. Cada Vivência contava com um grupo de mulheres envolvidas em projetos independentes de venda de roupa, joias, bonecas, livros, ou artesanato. Decerto, o Balé das lyabás não era apenas formado por Ludmila e Sinara, mas por todas as muIheres que participavam do projeto, fazendo parte de uma rede feminista e antirracista de apoio mútuo.

A segunda parte da sessão estava dedicada a uma aula de dança afro-brasileira ministrada por Ludmila Almeida. As coreografias desenvolvidas pelo Balé correspondem a uma linha de pesquisa da artista, que aborda as semeIhanças entre os itans (mitos ancestrais) e as experiências da vida cotidiana das mulheres no presente, a partir de um estudo da gestualidade correspondente ao caráter de cada orixá. Em cada Vivência, um pequeno grupo de percussionistas chegavam, para fazer o acompanhamento dos exercícios da aula de dança, produzindo outra camada de sentido no trabalho daquela sessão. Segundo Ludmila, "o corpo negro traz uma marca simbólica muito forte através da presença histórica das mulheres que estiveram antes do que nós. Nas Vivências atualizamos essa memória ancestral para gerar mudanças no nosso momento presente"21. Nas reflexões voltadas para a memória, o corpo e a prática da performance, Leda Martins aponta:

Dançar é performar, inscrever. A performance ritual é, pois, um ato de inscrição. Nas culturas predominantes orais e gestuais, como as africanas e as indígenas, por exemplo, o corpo é, por excelência, o local da memória, o corpo em performance, o corpo que é performance. Como tal esse corpo/corpus não apenas remete um hábito, mas também institui, interpreta e revisa o ato reencenado. Daí a importância de ressaltarmos nas tradições performáticas sua natureza meta-constitutiva, nas quais o fazer não elide $o$ ato de reflexão; o conteúdo imbrica-se na forma, a memória grafa-se no corpo, que a registra, transmite e modifica dinamicamente. O corpo, nessas tradições, não é, portanto, apenas a extensão de um saber reapresentado, e nem arquivo de uma cristalização estática. Ele é, sim, local de um saber em contínuo movimento de recriação formal, remissão e transformações perenes do corpus cultural. (MARTINS, 2003:76)

Enquanto Leda reflete sobre a prática performática dos corpos afrodescentes nos rituais, Ludmila propõe uma leitura outra da realidade mito-poética do Candomblé, conforme a perspectivas feministas, de modo a fortalecer a produção de presença dos corpos das mulheres negras em todos os âmbitos da existência. O corpo da mulher negra em dança é memória dinâmica, reavivada em cada movimento. Nas Vivências, dançar 
significava trazer de volta a experiência negra na sua multiplicidade e coreografar, historizar com o corpo a produção de saberes ancestrais das mulheres africanas, atualizando-os. Esse corpo-memória é sempre produzido na coletividade, ao contrário do corpo-indivíduo (branco ou embranquecido) concebido como um sujeito individual, independente e isolado, que tão frequentemente impõe-se nas sociedades ocidentais e ocidentalizadas como é a brasileira.

A dança transfere humanidade nesse "corpo acontecido" (RAMOS SILVA, 2017) negro, resgatando-o da área do não-ser e reconhecendo a imensidade da potência dele. Karina Vieira, ativista e blogueira de Meninas Black Power, após sua participação nas Vivências, escreveu:

O corpo preto incomoda. Por isso somos tolhidas, apontadas e muitas vezes envergonhadas quando temos que nos fazer presentes. A corporalidade se dá na vivência com o outro, se dá no conhecimento do lugar histórico que esse corpo está. Visibilidade e representatividade são problematizações que permeiam e conduzem o meu lugar de fala, pois quanto mais eu me vejo, quanto mais eu me sinto representada, menos o meu corpo ocupa um lugar estranho pra mim22.

Daí que ser e estar juntas nas Vivências devenham sinônimo. No filme Ôrí, Beatriz Nascimento (1989) reconhece esse sentido de comunidade afirmando que "o rosto de um é o reflexo do outro", "o corpo de um é o reflexo de outro e em cada um o reflexo de todos os corpos". As Vivências do Balé desvelam os preconceitos de cor e os privilégios da pigmentação, escondidos sob o manto do mito da democracia racial.

\section{A modo de conclusão}

Assisti a primeira Vivência em 2015, pela recomendação da investigadora feminista e professora da UNIRIO, a Dra. Angela Donini, pois eu simplesmente estava procurando aulas de dança afro-brasileira durante minha estadia no Rio de Janeiro. Voltando para casa, após a primeira sessão, eu me perguntei, "o que tem a ver tudo isto comigo?". Aos poucos fui compreendendo as múltiplas interpelações dessas mulheres na minha existência. Às vezes sinto que precisamos do deslocamento físico e de uma certa distância dos nossos contextos, para nos enxergar por meio das práticas de outras mulheres. As estratégias são diversas e eu escolhi habitar o lugar 
de estranhamento, para compreender os meus processos vitais enquanto pesquisadora, curadora e gestora cultural.

Assim, eu percebi que pouquíssimo sabia da história das mulheres da minha família. Daí em diante, toda vez que eu regressava em Valência (minha cidade natal, na Espanha), pedia para minha mãe espanar os álbuns da família e tecer os relatos da nossa história. As Vivências foram a primeira pedra de toque para eu refletir acerca do lugar de fala do meu grupo social, portanto, começar a pensar em branquitude. Uma localização, que não é fixa nem estável, mas complexa e em processo, e sempre dependente do espaço geográfico / geopolítico de onde seja enunciada.

O exercício de escuta radical e amorosa nas Vivências, me levou para falar em branquitude, enquanto sistema que atinge as dimensões do social, corporal, psicológico, econômico e político. Desta maneira, era irremediável admitir que não fui educada para me reconhecer europeia, mas simplesmente ser humano, usufruindo de uma série de direitos universais, que em definitivo, são os privilégios do grupo social pertencente à matriz de dominação. Europa é uma figuração extremamente complexa e não desprovida de contradições, paradoxos, relações de poder e geopolíticas no bojo dela. Porém, minha identificação devem um assunto de responsabilidade. A meu ver, o desafio de ser feminista corresponde com lutar contra o sujeito político feminista hegemônico, que habita em muitas de nós. Em um texto publicado recentemente declaro:

\footnotetext{
Durante o meu nomadar, fui compreendendo que o sujeito político feminista e antirracista constrói-se com base em uma ideia de mestiçagem cultural23 (incluindo o corporal sob um olhar não-biologizante, mas antes como a materialidade da subjetividade produzida nesse fazer), entendido de uma perspectiva anzalduana, isto é, enquanto lugar simbólico e material da ambiguidade, que por sua vez precisa da articulação multi-inter-transdisciplinar no desenvolvimento de qualquer prática, seja de investigação, quotidiana, artística, escritural ou social. Um espaço de criação ambíguo, maleável, de modo a permitir o fluir do pensamento, a invenção de outras línguas, o resgate da magia e esticar a armação epistemológico/ontológico do sujeito moderno. (MARUGÁN RICART, 2020: 220)
}

Com o Balé das lyabás aprendi que é possível magiar ensaios de outros mundos, imaginar modelos alternativos democráticos para as sociedades

23 De modo a evitar confusões, é importante salientar que a ideia de mestiçagem cultural que eu proponho nesse texto, nada tem a ver com o projeto de miscigenação fundador do modelo de nação brasileira. 
DIANA DOS SANTOS, Luana. Por um feminismo plural: escritos de Lélia Gonzáles no Jornal Mulherio. Gênero na Amazônia, Belem, № 4, pp. 226237, julho- dezembro 2013.

FEDERICI, Silvia. Calibán y la bruja. Mujeres, cuerpo y acumulación originaria. Madrid: Traficantes de sueños, 2010.

GOMES SILVA, Tauana Olívia; DE SOUSA FERREIRA, Gleidiani. E as mulheres negras? Narrativas históricas de um feminismo à margem das ondas. Estudos Feministas, Florianópolis, № 25 (3), pp. 1017-1033, setembro-dezembro 2017.

GONZÁLEZ, Lélia. Lélia fala de Lélia. Estudos Feministas, Florianópolis, $\mathrm{n}^{\circ}$ 2, pp. 383-386, 1994.

GRUPO CULTURAL BALÉ DAS IYABÁS. Release de apresentação. Documento interno, 2016.

KILOMBA, Grada. Memórias da Plantação. Episódios de racismo cotidiano. Rio de Janeiro: editora de libros Cobogó, 2019

LUGONES, María. Colonialidad de Género. Hacia un feminismo descolonial. In Walter MIGNOLO et al., Género y descolonialidad. Argentina: Ediciones del Signo, pp. 13-42, 2014.

MARTINS, Leda. Performances da oralitura: corpo, lugar da memória. Letras $\mathrm{n}^{\circ} 26$ - Língua e Literatura: limites e fronteiras, pp. 63-81, 2003.

MARUGÁN RICART, Paola María. Ejercicio Auto-etnográfico: blanquitud, mestizaje cultural y nomadismo feminista. Primeras indagaciones para el desarrollo de un pensamiento situado en movimiento. Revista Periódicus, Salvador de Bahía, nº12, v. 1, pp. 204-222, 2020.

MBEMBE, Achille. Crítica da razão negra. Lisboa: Editorial Antígona, 2014.

RATTS, Alex. Eu sou atlântica sobre a trajetória de vida de Beatriz Nascimento. São Paulo: Imprensa oficial do Estado de São Paulo, 2006.

RIBEIRO, Djamila. O que é lugar de fala?. Belo Horizonte: Feminismos Plurais, 2017.

RIVERA CUSICANQUI, Silvia. Un mundo Ch'ixi es posible. Ensayos de um presente em crisis. Buenos Aires: Tinta Limón, 2018.

SILVA BENTO, Maria Aparecida. Branqueamento e branquitude no Brasil. In Iray CARONE; Maria Aparecida SILVA BENTO (orgs). Psicología social do racismo - estudos sobre branquitude e branqueamento no Brasil. Petrópolis, RJ: Vozes, pp. 25-58, 2002.

SOUZA, Jessé. A radiografia do golpe. Rio de Janeiro: Leya, 2016. 
TREBISACCE, Catalina. Una historia crítica del concepto de experiência de la epistemologia feminista. Cinta de Moebio: Revista de Epistemología de Ciencias Sociales, pp. 1-14, 2016.

VIEIRA, Karina. Corporalidade e (re)conhecimento. 2015. Disponível em < https://www.geledes.org.br/corporalidade-e-reconhecimento/ > WERNECK, Jurema. Nossos passos vêm de longe! Movimentos de muIheres negras e estratégias políticas contra o sexismo e o racismo. Open Edition Books, pp. 151-163, 2016.

\section{REFERÊNCIAS AUDIOVISUAIS}

Entrevista realizada a Ludmila Almeida no programa "Estudo Móvel" da TVBrasil, o 14 de novembro de 2016. Disponível: http://tvbrasil.ebc. com.br/estudiomovel/episodio/empoderamento-feminino-atraves-da-danca

Reportagem do Balé das lyabás no programa "Para Todos" da TvBrail, realizada o dia 6 de junho de 2015. Disponível: https://tvbrasil.ebc.com. $\mathrm{br} /$ paratodos/episodio/a-primeira-dama-do-samba-dona-ivone-lara-esta-no-paratodos\#media-youtube-1

RAMOS SILVA, Luciane. O negro na dança - Diálogos Ausentes, 2017. Disponível: https://www.youtube.com/watch?v=CkfOpgnmfLE Ôrí, dirigida por Raquel Gerber, roteiro e voz em off Beatriz Nascimento, 1989. 